\title{
Mobile Learning, Cognitive Architecture and the Study of Literature
}

\author{
Susan Smith Nash, \\ Excelsior College, Albany, NY
}

susan@beyondutopia.com

\begin{abstract}
The growing popularity of mobile devices, coupled with the ever-increasing number of highquality e-books available for free download is causing a re-examination of core curriculum and instructional philosophies. Perhaps the most - making "great books" programs available and accessible - newly interesting, despite misgivings and political correctness of the last few decades. Distance learning via mobile devices, which incorporate some of the techniques of television and film, has made the classics of literature available and allowed people to have access to classics at a very low cost. At the same time, it has re-animated debates about the nature of study of comparative literature in a globalized world.
\end{abstract}

Keywords: m-learning, mobile learning, podcasts, video casts, great books, humanities education

\section{Introduction}

This paper investigates the problem of how best to achieve learning outcomes of reading comprehension, recall, critical thinking, and synthesis in the study of literature by incorporating mobile learning that accommodates cognitive architectures, as described by Sweller's cognitive load theory, Mayer's multimedia learning theory, Paivio's dual coding theory and others.

\section{Overview of the Applications of Mobile Learning to the Study of Literature}

The definition of mobile learning has evolved with the advent of new technology. While mobile learning could, in its broadest sense, be said to cover books, CD-ROMs, radios, and laptops, most researchers in the field of educational technology consider mobile learning, or m-learning, to be a subset of e-learning (Laouris \& Eteokleous, 2005). What differentiates mobile from electronic is the nature of the technology. S. Geddes (2004) has provided a succinct definition: "mLearning is the acquisition of any knowledge and skill through using mobile technology, anywhere, anytime, that results in an alteration in behaviour" (Geddes, 2004, p. 1).

Material published as part of this publication, either on-line or in print, is copyrighted by the Informing Science Institute. Permission to make digital or paper copy of part or all of these works for personal or classroom use is granted without fee provided that the copies are not made or distributed for profit or commercial advantage AND that copies 1) bear this notice in full and 2) give the full citation on the first page. It is permissible to abstract these works so long as credit is given. To copy in all other cases or to republish or to post on a server or to redistribute to lists requires specific permission and payment of a fee. Contact Publisher@InformingScience.org to request redistribution permission.
Other definitions of m-learning have been developed, but instead of focusing on the technology, they emphasize the characteristics of the learning process. Instead of looking at technology and behavioral change, they examine how mobile technology has allowed a shift in learning strategies and approaches.

For the purposes of this paper, mobile learning denotes instructional content or 
activities that are delivered on handheld (or mobile) devices, that accommodate limited multimedia delivery, primarily in the form of audio, images, animations (video), and text. Popular mobile devices include those capable of playing files that are often downloaded from the Internet on a computer and then uploaded onto the device where it is then taken with the individual, who may play the files while not directly connected to a computer. Audio and video files may be played on handheld computers, audio file players such as iPod, and handheld devices that play video files. New hardware is always being developed which accommodate more simultaneous functions, larger files, and more robust access through phone and high-speed satellite connections. While all handheld technologies are expanding, the fastest development has been in the incorporation of connectivity and functionality, envisioned in the form of smartphones or wireless handhelds. Mobile learning also can accommodate ebooks, where text files can be read on pdf files on handheld devices that include pdf or ebook reader software.

\section{e-Learning vs. $m$-Learning}

According to Laouris and Eteokleous (2005), e-learning was dominated by the following terms: "multimedia, interacttive, hyperlinked, media-rich," (Laouris \& Eteokleous, 2005, p. 3). Mlearning terms, however, exhibit a shift away from a media immersion experience, or a structured, benchmarked set of activities, to words that express what are perceived as the primary attributes of a very different experience: "spontaneous, intimate, situated, connected, informal, lightweight, personal," (Laouris \& Eteokleous, 2005, p. 3).

Because "mobility is about increasing a learner's capacity to physically move their own learning environment as they move" (Barbosa \& Geyer, 2005), the nature of the learner's interaction with instructional content is altered. Instead of immersing oneself into an environment that floods the senses with stimuli, such as that of a virtual reality experience provided by simulations and games in robust computer systems, or interacting with multiple users within a complex learning management system, the m-learner engages with the content in a constantly changing environment.

Thus, if designed well, the m-learning course takes advantage of constantly changing instructional contexts or environment to allow the learner to connect the content so that he or she is compelled to integrate the world outside with the world of material on the device in order to successfully demonstrate the achievement of learning objectives. Specifically, the well-designed mlearning program brings together the leaner's physical environment (constantly changing, since it is mobile), with the concepts to be understood and processed.

With mobile technologies, m-learner can be conceptualized as an individual using equipment to take readings, gather data, and to integrate data and knowledge to create a map. This process is literal and metaphoric. The "map" is the product, or the outcome of any learning activity. It is constructed in a spontaneous, problem-solving process.

\section{Literature and Distance Learning: From Books to e-Learning and m-Learning}

The impact of a changing instructional strategy and a constantly evolving set of technological breakthroughs can have an impact on traditional courses such as literature. In the case of literature, distance learning in its most basic form included books and correspondence with an instructor. 
Table 1. Comparison of e-Learning and m-Learning content and outcome attributes.

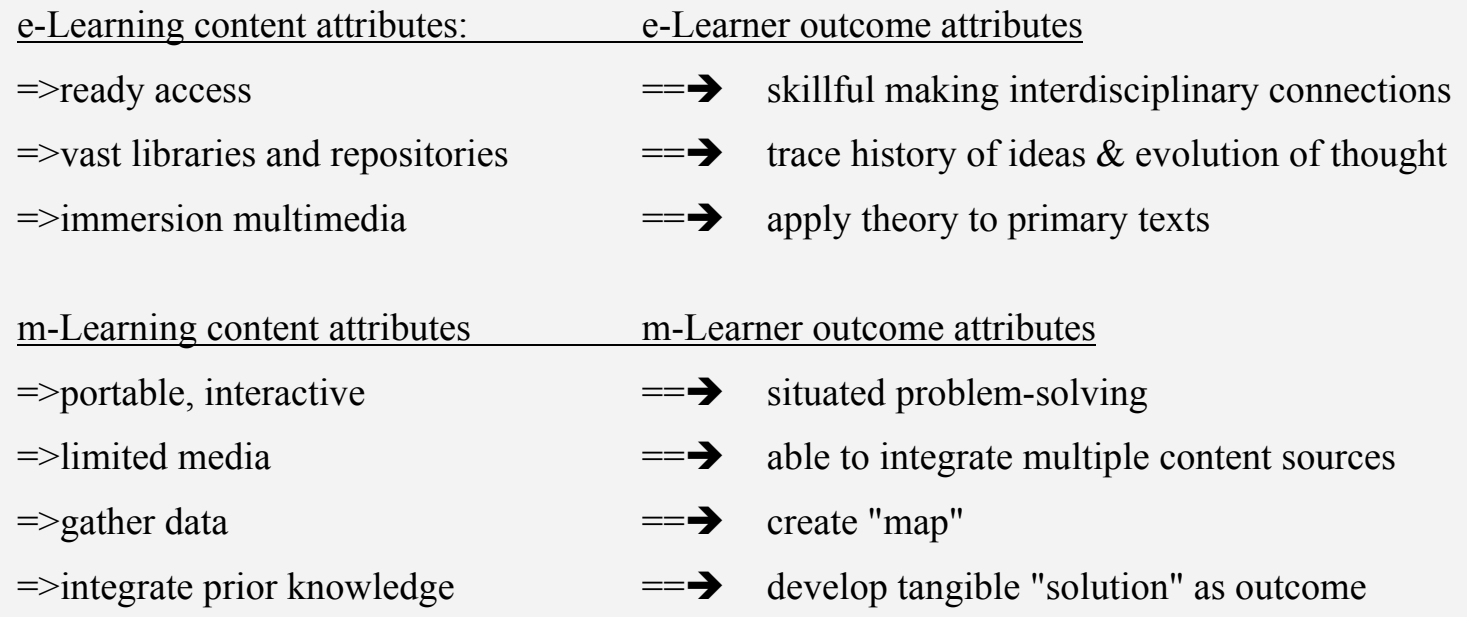

With the advent of computer-based training and learning (CBT) and e-learning, the instructional strategies changed. Access to primary texts and abundant secondary texts became possible in a way that had never been envisioned before, thanks to repositories such as Project Gutenberg, which provides e-texts free of charge and libraries of secondary sources. Instructional strategies tended to emphasize the richness of contexts. For example, an e-learning course, or a CD-ROM course on British Romanticism could also include videos, presentations, music, and images of art and architecture.

In addition to affecting instructional strategies, online technology influenced learning strategies and learner outcomes (Table 1). With inexpensive access to texts, abundant availability of texts, and immersion multimedia experiences, learners became adept at making interdisciplinary connections and tracing provenances. Students using CD-ROM or online repositories demonstrated that they were also skillful in applying theory to literary texts, thanks to the availability of highquality secondary sources.

Advances in information technology and computers changed instructional strategies and learner outcomes yet again. With the advent of mobile devices - handheld computers and devices capable of reading ebooks - digitized texts became available via download or through memory cards.

The first responses to mobile devices by educators and researchers were mixed. Some were enthusiastic, as were Looney \& Sheehan (2001), who emphasize that "students who are literally anywhere in the world will have access to the same content as does the student on campus, whether that access is through the faculty Web site, the college bookstore or the digital library" (Looney \& Sheehan, 2001, p. 3). While educators praised the low cost and expanded access to literary works (Looney \& Sheehan, 2001), they also pointed out how incapable the handheld devices were of providing the kind of immersion experience available through computer-based training and e-learning (Hawkins, 2000).

In fact, one can argue that the tendency to measure the quality of an educational experience by the degree to which one has an immersion experience is what hampered initial adoptions of ebooks, despite the increase in both volume and extent of primary and secondary sources. Hawkins (2000) and others regularly listed "unattractive page formats" (Hawkins, 2000, p. 17) as the primary disadvantages of ebooks. There was little thought or consideration given to how the content would be used, except in functional terms (lightweight, portable, long battery life), and where (in 
trains, planes, hotel rooms) (Hawkins, 2000). Providing students with low-cost access to a vast array of works was still the main focus (Crane, 2000).

The portability and improved access of mobile devices encouraged many researchers to point out that the real benefits of mobile learning had to do with enhanced collaboration, improved abilities to incorporate situated learning by using the environmental inputs in order to solve a problem or create a "map" of a concept, process, or solution. S. Geddes points out that collaborative and dynamic approaches to mobile learning lead to the attainment of metacognitive skills, which include reflection in action, reflection on action, and anticipation of future action (Geddes, 2004, p. 7). The ability to work with multiple types of input from mobile devices to identify, comprehend, categorize, and synthesize information "on the fly" is an important and largely unexplored value of m-learning.

\section{Literature, ebooks, and Portable Multimedia Components}

Students and scholars of literature have benefited from the availability of royalty-free primary texts which are often available for free for download on sites such as Project Gutenberg. However, despite the obvious cost advantages of ebooks, the early versions that consisted of little more than text were met with less than expected enthusiasm.

As mobile technologies evolved (Table 2), instructional strategies have shifted, especially as new capabilities have been introduced and adopted by users. Later versions of ebooks often include linked timelines, glossaries, and images. Multimedia presentations may even include simulations or games built on a particular novel, such as Beowulf. Audio books are also available. Some works of literature may have accompanying repositories of images, video snippets or full-length movies.

Table 2. List of Mobile Technology Capabilities

--download, store, display text

--download, store, display images

--download, store, play audio

--download, store, play video

--download, store, play games and simulations

--download, store, and play images, audio, video-enhanced e-books

--take, store, share audio, video, text, images

--receive and share instant messages (text, image, video)

--make telephone calls

--record, store, process, and share data (GPS, images, temperatures, pressure, etc.)

--edit, modify, alter shared text and images

The challenge is to create an effective instructional strategy that allows the learner to maximize the use of available multimedia components and to use them to achieve learning outcomes. The learning goals of reading comprehension, recall, critical thinking and synthesis are most likely to be assessed by means of interactive quizzes, short responses, and written papers.

While mobile technologies make it possible to use numerous devices in the field, with maximum flexibility and portability, the sheer number of variables (types of devices, environmental varia- 
tions, context differences, blend of components), creates a number of potential pitfalls for the instructional designer and learner.

It is highly likely that the learner can be distracted, or unable to focus. Designing learning activities around what research has revealed about cognitive architecture is an effective strategy for achieving better learning outcomes.

\section{Cognitive Architecture and Mobile Learning Instructional Strategies}

\section{Mayer's Multimedia Theory}

Mayer and Moreno (1998) have centered their work with multimedia and learning around a cognitive theory of multimedia learning. Their "Split Attention Principle" explains why people learn more when learning has involved more than one way of presenting information. Mayer and Moreno found that pictorial and verbal representation are held in working memory at the same time. Applied to the study of literature, it is most effective to have images and audio. However, the images and audio should not replicate or duplicate the text. Instead, audio, animations, images, and text should encourage the mind to make connections.

For example, a presentation of Shakespeare's Romeo and Juliet could include an audio recording, images and scenes (or brief snippets) of video, symbols, and color coding. Thus, students will have better recall of the elements of the narrative when the instructional material does not require them to split attention. Instead, the material will reinforce and facilitate the making of connections so that they are able to answer questions that involve comprehension of the text, and to write essays that require synthesis. The multimedia approach is effective when asking students to later write papers that compare and contrast elements within the work of literature, or to take a position and support it with evidence drawn from the work.

\section{Sweller's Cognitive Load Theory}

According to the results of many experiments with students in mathematics and psychology, to be effective, one should present material using more than one channel of media. This is, in essence, a way to manage cognitive load during problem solving (Sweller, 1988).

Cognitive load balancing is important in order to avoid what researchers have called the "split attention effect" (Mayer \& Moreno, 1998). The split-attention effect occurs when too many elements are presented at the same time, which causes learners to shift their focus back and forth between two types of information (Sweller, 1994). In order to avoid the split-attention effect, one should create diagrams or visual elements that are fully understandable without an explanation. If the diagram is understandable, the accompanying audio, video, or text will actually enhance understanding, learning, and performance of learning activities.

As applied to m-learning, a map, diagram, or image could be displayed on a handheld device while an audio book adds details and elaboration that is not necessarily a part of the diagram. The elaboration could also incorporate the environment. For example, the study of Arthur Miller's Death of a Salesman or David Mamet's Glengarry, Glenross could incorporate a visit to a local telemarketing center, or even a video snippet of a call center in America (or outsourced). The learner would be encouraged to make connections and to synthesize the work of art and cultural ideals that inform the work, such as the American dream. 


\section{Mayer and Moreno's Modality Principle}

Mayer and Moreno (1998) found that the learning outcomes could be optimized using multimedia, if the material is presented in accordance with the "Modality Principle" which suggests that students learn better when verbal information is "presented auditorily as speech rather than visually as on-screen text" (Moreno \& Mayer, 2000, p 4).

However, Mayer and Moreno also find that it is counterproductive to incorporate concurrent multimedia presentations. The problem is that the learner is forced to hold information in working memory and transfer it back and forth, and thus loses recall and is unable to form schema or other organizing mechanisms.

Competing multimedia is a common flaw of m-learning design. For example, animated presentations that also include embedded videos, while allowing instant messaging or and whiteboards result in distractions. What the learner is most likely to focus on is the performative aspect, and any interactive elements tend to prevail in terms of holding one's attention. For example, in a situation where the student is simultaneously watching listening to a lecture and typing instant messages for collaboration, the instant messaging will tend to prevail, unless the audio has something to do with the instant message task, and the learner is responding to and sending information in response to information she has obtained by listening to the audio.

\section{Mayer's Spatial Contiguity Principle}

Mayer (1997) found that if verbal and visual explanations are integrated, learning is more effective. The implication for mobile learning and literature is that the images should have clear captions as close as possible to the part of the image with the most semiotically-rich elements. As a result, with labels on the pictures, the learner will make connections which will facilitate comprehension. It can also be a cue for recall, and also an aid for classification and the creation of schema.

For example, Shakespeare's Henry $V$ could include an audio of Henry's speech to the troops before the Battle of Agincourt. Images or videos of the battle would include clear labels. The text could also take the analysis a step further and make a connection to archetypes and the hero, with the clear connection that Henry $V$ is an example of a hero and heroic behavior.

\section{Paivio's Dual Coding Theory}

Paivio (1969) reported the results of his research in media that focused on elaboration. He theorized that elaboration had more than one form. The first form of elaboration is built on verbal associations. The second involves creating a visual image (Paivio, 1969). The visual image can be generated by the learner's own imagination. However, self-generated images are not as effective in demonstrating the ability to uniformly recall text, demonstrate comprehension, or discuss possible meanings or interpretations. Paivio posited that verbal and visual elaboration employs two completely independent memory codes.

Paivio's theory has been applied to the use of visual mnemonics to learn foreign vocabulary words.

The Dual Coding Theory could also be applied to literature and the use of mobile devices. For example, in an e-book, themes and key ideas or characters in a novel could be connected to visual codes such as colors or symbols. Embedding auditory cues such as musical motifs or male or female voices within the e-book could also reinforce key ideas through colors or other visual schema. Paivio suggests that using dual coding for elaboration will result in effective use of long-term memory (Paivio, 1986). 
For example, the study of Shakespeare's Othello could include audio presentation, with distinctive voices for Othello and Desdemona. Images or symbols of real or imagined guilt or innocence - Desdemona's handkerchief, the pattern of strawberries on a white background could be graphically portrayed at key points in the text. Other symbols could be found to illustrate Othello's feeling of "otherness," Desdemona's fear of lost honor, her potential for betrayal, and her own "otherness" due to gender - could help the student identify and elaborate the major themes in the work.

\section{Conclusion}

An understanding of cognitive architecture helps develop effective instructional strategies for both e-learning and m-learning. To understand cognitive architecture is especially important in the case of the use of mobile devices and instructional material to assure that the "alteration of behavior" described in Geddes' (2004) definition of m-learning leads to desired learning outcomes.

The challenge is particularly keen in the case of the study of literature that utilizes e-books because the tendency is to utilize the texts in the same way that one would use a printed book in a traditional face-to-face educational setting, where it is accompanied by lectures, or as one would use a text in computer-based learning or training and e-learning, where the book is accompanied by robust video, simulation, and interactive learning activities.

Looking at cognitive architecture and how the mind processes multimedia can provide insight into effective learning practices, and can facilitate the development of effective outcome-focused instructional strategies.

\section{References}

Barbosa, D. N. F, \& Geyer, C. F. R. (2005). Pervasive personal pedagogical agent: A mobile agent shall always be with a learner. Proceedings of the IADIS International Conference Mobile Learning, Malta 281-285.

Crane, E. (2000). eBook Central takes a classic approach to handheld literature. Education in hand, December, 22-23.

Geddes, S. (2004). Mobile learning in the 21st century: Benefit for learners. Knowledge Tree e-journal. Retrieved April 9, 2007, from https://olt.qut.edu.au/udf/OLTCONFERENCEPAPERS/gen/static/papers/Cobcroft_OLT2006_paper.p df.

Hawkins, D. (2000). Electronic books: A major publishing revolution. Online, July/August, 14-28.

Laouris, Y., \& Eteokleous, N. (2005). We need an educationally relevant definition of mobile learning. Retrieved April 9, 2007, from www.mlearn.org.za/CD/papers/Laouris\%20\&\%20Eteokleous.pdf.

Looney, M., \& Sheehan, M. (2001). Digitizing education: A primer on ebooks. Community College Week, 14(2), 1-4.

Mayer, R. E. (1997). Multimedia learning: Are we asking the right questions? Educational Psychologist, $32,1-19$.

Mayer, R. E. \& Moreno, R. (1998). A split-attention effect in multimedia learning: Evidence for dual processing systems in working memory. Journal of Educational Psychology, 90, 312-320.

Moreno, R., \& Mayer, R. E. (2000). A coherence effect in multimedia learning: The case for minimizing irrelevant sounds in the design of multimedia instructional messages. Journal of Educational Psychology, 97, 117-125.

Paivio, A. (1969). Mental imagery in associative learning and memory. Psychological review, 76, 241-263. 
Mobile Learning, Cognitive Architecture and the Study of Literature

Paivio, A. (1986). Mental representation: A dual coding approach. Oxford, England: Oxford University Press.

Sweller, J. (1994). Why some material is difficult to learn. Cognition and instruction, 12, 185-233.

Sweller, J. (1988). Cognitive load during problem solving: Effects on learning. Cognitive Science, 12, 257285.

\section{Biography}

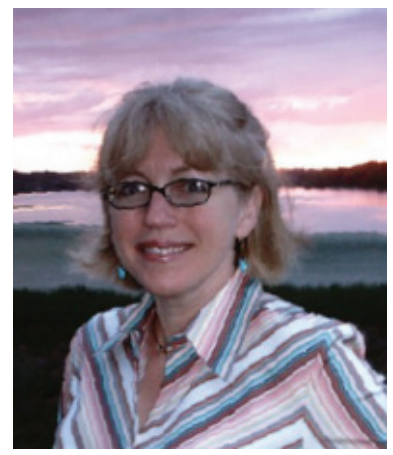

Susan Smith Nash has developed and administered distance education programs incorporating hybrid solutions, as well as e-learning and mobile learning, since 1995. Nash's latest book is Excellence in College Teaching and Learning: Classroom and Online Instruction, coauthored with George Henderson, to be published in 2007 by Charles C. Thomas. Her previous book, Leadership and the E-Learning Organization is available online and in print. 